\title{
A Study of Airlines Customer Satisfaction in the Kingdom of Saudi Arabia
}

\author{
Sultan Althaqafi \\ Hani Ali Bashammakh \\ Youssif Albarmawi \\ Khalid khan
}

Master Students at College of Business Administration,

University of Business \& Technology, Jeddah, Saudi Arabia

\section{Sayeeduzzafar Qazi (Professor)}

College of Business Administration,

University of Business \& Technology, Jeddah, Saudi Arabia

\begin{abstract}
The quality of service plays a major role in service industry especially when it comes to customer satisfaction level. This paper focuses on investigating the customer's satisfaction levels towards services provided by Saudi Airlines. For this purpose, a questionnaire was developed and distributed among 165 domestic as well as international passengers at the airport. After scrutiny, it was found that only 159 questionnaires were completed in all respects and were included in the study. The data collected afterwards were analysed in order to measure the actual satisfaction level of customers. It was found that the domestic as well as the international passengers of Saudi Arabia airlines were not happy and satisfied with the services provided by the airlines. Thus, the major problem area includes baggage handling, treatment of passengers at airport in case of any grievances, food quality, and entertainment on board. Based on the outcome of the research, certain strategies to overcome such issues were recommended by the authors.
\end{abstract}

Keywords: Customer Satisfaction, Airlines, Baggage Handling, Online Entertainment, Pricing

\section{Introduction}

The airline industry has made significant contributions towards the economic development of the country (Jahmani, 2017). However, quality of service in the aviation industry is a competitive advantage for airlines to 
increase profitability, and the most important factor in the industry is passengers. In order for the airlines to adopt their passengers, companies must understand the needs of passengers to provide good and high quality services (Jahmani, 2017). This research attempts to provide insight into current customer satisfaction and to assess customer satisfaction with services provided in the aviation industry.

"Consumer satisfaction has long been recognized as the core of the marketing concept" (Oyewole, 2015). Thus, it is described as "a complex and elusive phenomenon" (Peterson \& Wilson, 1992). "A firm should be able to increase customer satisfaction by improving its customer service" (Steven, Dong \& Dresner, 2012) because customer satisfaction is a key factor in business sustainability (Peterson \& Wilson, 1992). Furthermore, "to be able to interpret and effectively utilize customer satisfaction ratings, it is necessary to understand what determines them as well as know what variables and/or factors related to them".

Consequently, there are many definitions given to the term "customer satisfaction" with one, given earlier, that stresses more on cognitive process. Recently, consumer satisfaction research has gone beyond cognitively toned formulations to recognizing the affective nature of satisfaction. Suhartanto and Ariani Noor quoted Tse and Wilton (1988, p.204) defining it as "consumer's response to the evaluation of the perceived discrepancy between prior expectation and the actual performance of the product as perceived after its consumption". While other variations of the definition of customer satisfaction have been presented by scholars, most of the definitions agree with the fact that satisfaction is a complex human process, involving cognitive, affective, and other undiscovered psychological and physiological dynamics (Bhattacharya \& Singh, 2008).

Service and quality play a major role in customer satisfaction in service industry such as airlines industry. In a study related to the customer retention in airline industry that was carried out by Climis (2017), the researcher had introduced some factors related to customer satisfaction such as: loyalty reward program, safety, and quality attribute in airline industry. Moreover, according to Khan and Khan (2014), the quality of service in the airlines industry in Pakistan has a significant influence on customer behavior towards purchasing tickets or using services from any airline company. Such services may include the airline employee's attitude, pricing of the tickets as well as the services or the menu provided on the aeroplane. Thus, this tends to have a significant effect on the customer's decision to choose among the available offers provided by airlines firms which would consequently affect the income of those airline firms. 


\section{Literature Review}

After conducting 493 surveys, Raghda Climis stated that such factors may have a significant impact on customer satisfaction in north Cyprus. Using a survey of 382 passengers, Kos et al. (2017) examines customer satisfaction and its antecedents and consequences in the context of the airline industry. The relationships among airline tangibles, quality of personnel, satisfaction with the airline, the intention to repurchase, and the intention to recommend the airline were examined. The findings indicate that tangibles and personnel quality positively affect satisfaction, and satisfaction positively influences intentions to both repurchase and recommend. The key contribution is to test the moderating effect of the airline type: a low-cost vs. a full-service carrier. The results reveal a significant moderating effect of airline type on two relationships: personnel quality - satisfaction - and repurchase intention. Specifically, the positive effect of the quality of personnel on satisfaction is weaker for the low-cost versus full-service airline. On the other hand, the positive effect of satisfaction on repurchase intent is stronger for the low-cost airline. The study also discusses implications for airline carriers.

In addition, Ganjihal (2016) conducted a study on 450 participants about customer satisfaction in airlines industry using a case study of the British airways. The author's finding was similar to other studies which indicated that customer satisfaction is directly related to the service quality provided by any airline company.

Gambo (2016) introduced SERVQUAL model which concentrated on measuring the passenger's satisfaction in five dimensions such as responsiveness, reliability, in-flight service, check in process, and baggage handling service. However, after conducting a survey on 400 samples, it was observed that those factors are the most significant factors that affect the customer satisfaction in Nigeria.

Furthermore, Elias, Mohamed and Arridha (2015) investigated the online services provided by airline industry in Malaysia on 213 travelers in relation to customer satisfaction. The research has considered several online services such as responsiveness, quality of information, trust, and tangibility. This study has showed that whenever such quality services are provided by an airline company, the customer will become more loyal to it.

Similarly, Alotaibi (2015) in his study has emphasized that the focus on customer satisfaction in airlines industry provides the airline companies with great competitive advantages. Alotaibi also suggested that the airlines companies should make use of "AIRQUAL" scale on 500 respondents which is considered to be a tool used to measure the customer satisfaction for any airline company.

Moreover, according to Khan and Khan (2014), the quality of service in the airlines industry in Pakistan has a significant influence on customer 
behavior towards purchasing tickets or using services from any airline company. Such services may include the airline employee's attitude, pricing of the tickets as well as the services or the menu provided on the aeroplane. As prior stated, this would significantly affect the customer decision to choose among the available offers provided by airlines firms which would consequently also affect the income of those airline firms.

Clausen et al. (2010) provides a thorough review of the current stateof-the-art within airline disruption management of resources, including aircraft, crew, passenger, and integrated recovery. An overview of model formulations of the aircraft and crew scheduling problems was presented in order to emphasize the similarities between solution approaches applied to the planning and recovery problems. A brief overview of research within schedule robustness in airline scheduling was included in the review. This is because this proactive measure is a natural complement to disruption management.

Daft and Albers (2013) developed a measurement framework that synthesizes the airline and strategy literature in a bid to identify relevant dimensions and elements of airline business models. The applicability of this framework for describing airline strategies and structures and, based on this conceptualization, for assessing the potential convergence of airline business models over time is then illustrated using a small sample of five German passenger airlines. For this sample, the perception of a rapprochement of business models can be supported. Therefore, this paper extends the mostly qualitative and anecdotal literature on convergence in the airline industry and it provides a platform for further empirical convergence studies.

Wu and Cheng (2013) conducted a study to enhance and understand the service quality in the airline industry by developing a conceptual framework and measurement scale. Based on an extensive literature review, qualitative and empirical research, a hierarchical model of service quality for the airline industry is proposed. Analysis of data from 544 passengers indicates that the proposed model fits the data well. Reliability and validity of the measurement scale were established using a pilot test and the substantive survey. However, this study extends the literature on service quality in the fields of transportation management by providing a comprehensive framework and measurement scale.

Laming and Mason (2014) investigated the application of the concept of customer experience to the airline industry and the extent to which airline brands are meeting up with customer experience. The literature shows that the concept of customer experience is not well understood and do not have a clear and consistent definition. The purpose of customer experience is identified as to deliver satisfaction throughout the customer experience that, in turn, leads to brand loyalty and advocacy. The customer experience concept is applied to the airline industry. In order to measure its performance, a study was 
undertaken using International Air Transport Association data collected over a twelve-month period from a sample size of 18,567 passengers on fifteen major full-service airlines in Europe, Middle East, and Asia. The elements of the airline passenger journey most strongly related to overall satisfaction, loyalty, and advocacy were, for most airlines, cabin features followed by crew (for satisfaction) and inflight food and drink (for loyalty and advocacy). The analysis did not identify strong effects from the impact of airline continent, individual airline, and flight class. The relationships between the passengers' satisfaction ratings for specified elements of the journey and the overall satisfaction, loyalty, and advocacy were not moderated by flight class.

\section{Objectives of the Study}

To measure the overall customers' satisfaction level in airlines industry in Saudi Arabia by:

- Investigating males' and females' satisfaction level towards the services provided by the airlines in Saudi Arabia.

- Learning the impact of the services provided by the airlines in Saudi Arabia on the domestic travelers and international travelers.

\section{RESEARCH METHODOLOGY SAMPLE}

The research was conducted on 165 randomly selected passengers of Saudia Airlines for International as well as domestic flights. After scrutiny of the filled data, 6 questionnaires were rejected due to various reasons like incomplete information, wrong entries, etc. The remaining 159 cases were used in this study. However, the respondents were divided on the basis of certain demographic characteristics.

\section{PROCEDURE}

Data was collected by survey method at Airports from both Domestic as well as International Saudia Airlines Travelers. They were asked to properly go through the instructions and fill the given questionnaire based on their experience with Saudia Airlines.

\section{TOOLS USED}

A questionnaire was developed to identify the satisfaction level of Domestic as well as International Saudia Airlines Passengers departing or arriving at the Airport. A total of 12 questions were framed related with the services and perception of the travelers using Likert type scale.

The data was analyzed by using suitable statistical tools to achieve the objective of the research. 


\section{RESULTS AND DISCUSSIONS}

\section{Gender}

The total number of respondents was evaluated to be 159 participants. Around 70 percent were estimated to be males, which is equivalent to 111 responses. On the other hand, the female responses were accumulated for the remaining 30 percent which is equivalent to 48 responses. Both percentages are better illustrated in the pie chart below.

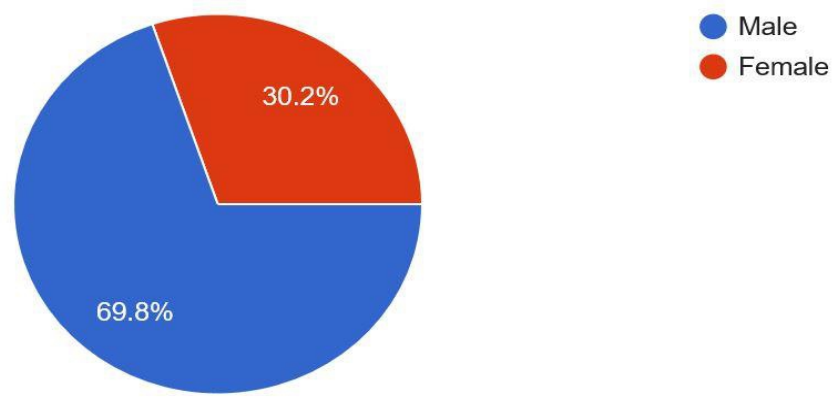

Figure 1. Sample's Gender

\section{Age}

The figure below demonstrates that $32 \%$ of the sample was between 18-28 years old, $34 \%$ were between 29-39 years old, $19 \%$ were between 40 50 years old, $13 \%$ were between 51-61 years old, while only $2 \%$ were more than 62 years old.

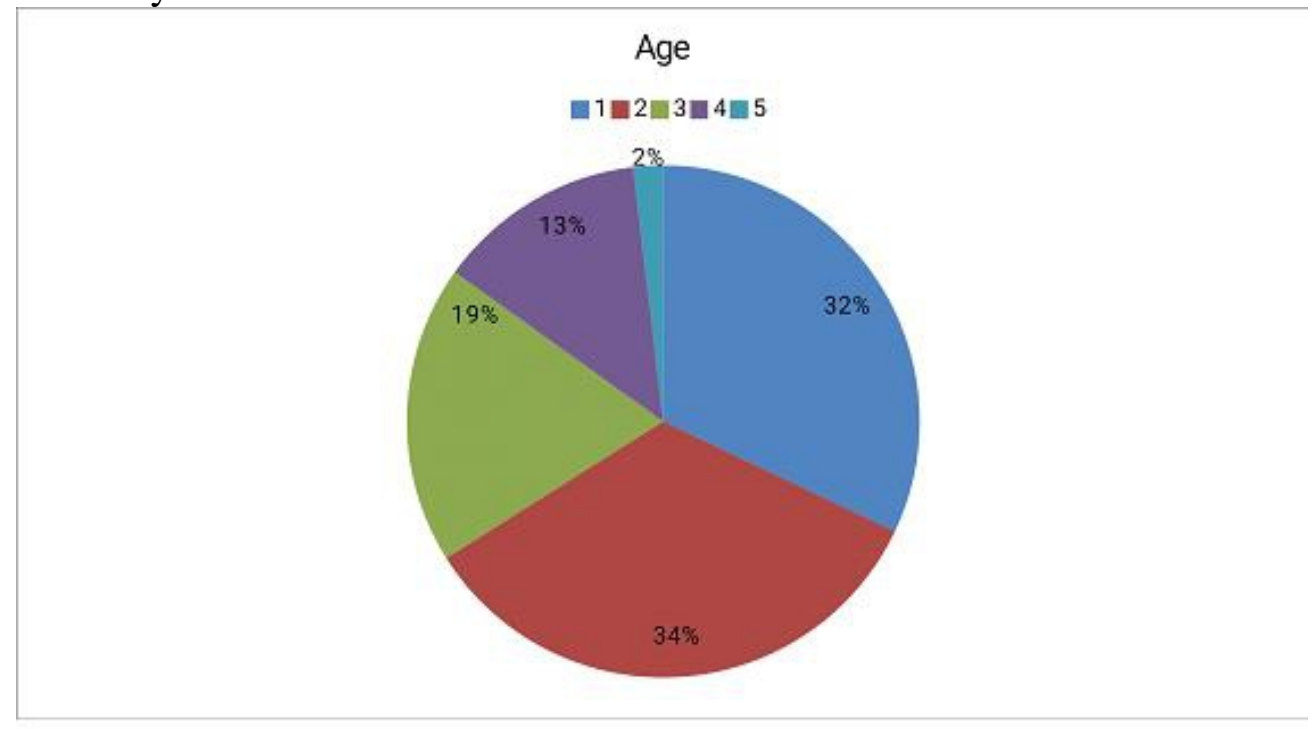

Figure 2. Sample's age 
- Travelling Type

Travelling: The total number of respondents was evaluated to be 159 participants. Around 54 percent were estimated to be international travelling which is equivalent to 85 responses. On the other hand, the female responses were accumulated for the remaining 46 percent which is equivalent to 73 responses. Both percentages are better illustrated in the following pie chart.

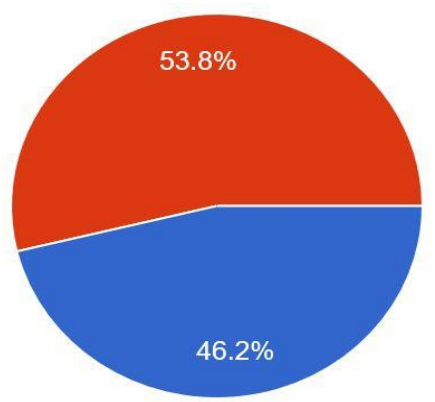

Figure 3. Sample's travelling

\section{Level of Satisfaction's Questions}

Ten questions were included in this section for the purpose of evaluating the level of satisfaction for each of the selected services that was provided by airlines in Saudi Arabia. However, the ten questions will be individually analyzed as follows:

\section{The Ability of Airline to Handle the Baggage of the Passengers}

The 159 participants were asked to rank their satisfaction towards the airline's ability to handle the baggage of the passengers. The scale of rating included five options which ranges from "strongly dissatisfied" to "highly satisfied" (i.e. " 1 " strongly dissatisfied, "2" dissatisfied, "3" neutral, "4" satisfied and " 5 " Highly satisfied). Consequently, the scaling technique was used again for all the following nine questions that investigated the level of customer's satisfaction towards the services provided by airlines. However, when the customers were asked about the passengers' baggage handling, the majority of 53 percent were dissatisfied with the service of baggage handling, while 25 percent were neutral and 22 were satisfied as shown in Figure 4. 


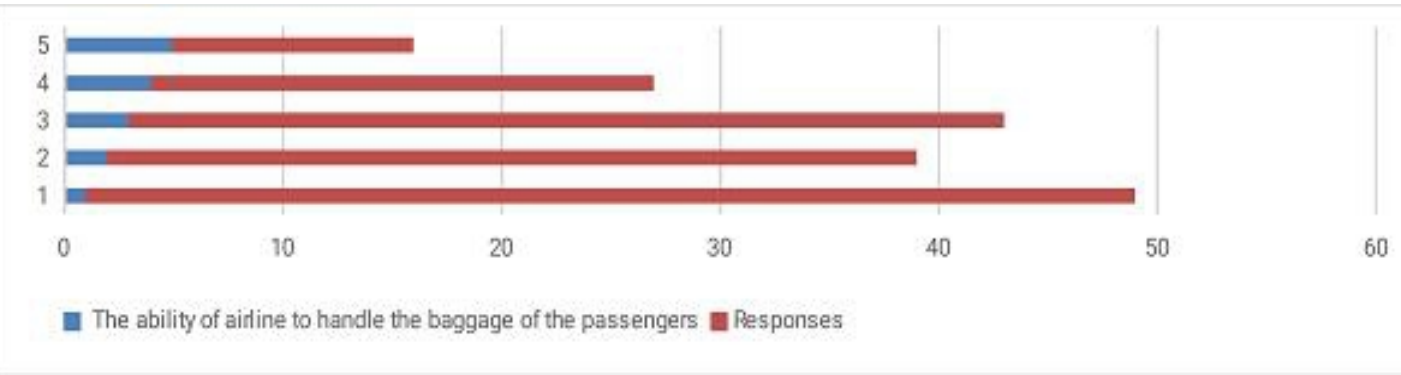

Figure 4. Baggage handling graph

\section{The Satisfaction Level with the Arrival Baggage Services}

The bar graph below shows the customers' satisfaction level on the service of arrival baggage. The chart clearly highlighted that 48 participants were neutral towards such a service. Meanwhile, 67 participants were dissatisfied and 44 participants were satisfied which is almost equivalent to the neutral responses.

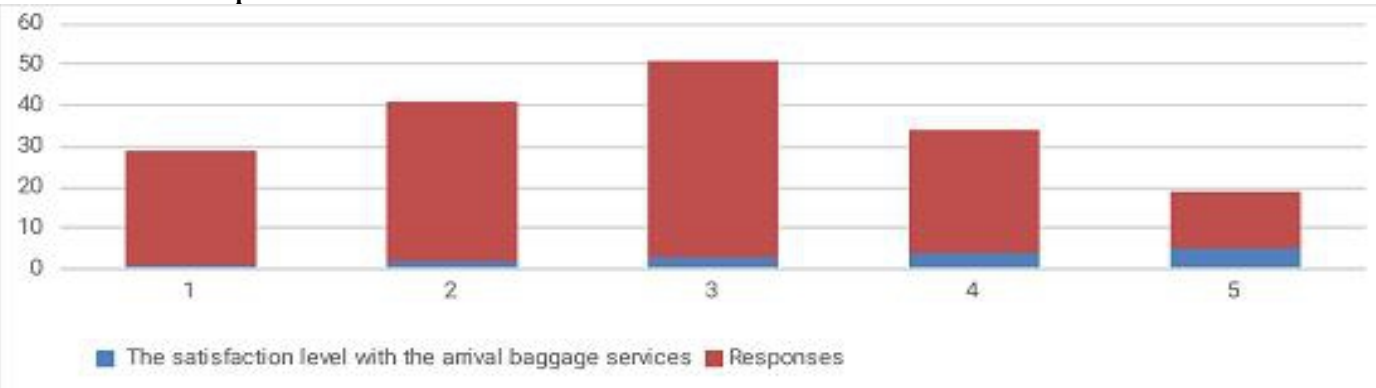

Figure 5. Arrival's baggage service graph

\section{The Satisfaction Level with the Flight Time Management of Airline}

Surprisingly, when the travelers were asked about their satisfaction level with the flight time management of airline, the majority of passengers of 36 percent were satisfied as can be demonstrated in the following bar graph. However, the dissatisfaction level was lower by 33 percent and the response of neutral was accumulated based on 49 responses.

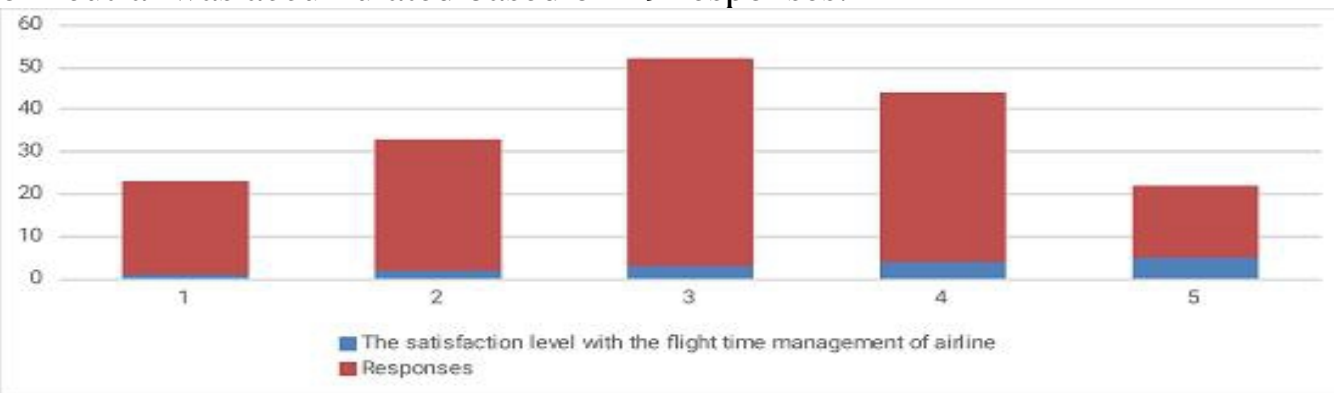

Figure 6. Satisfaction with flight time graph 


\section{The Satisfaction Level with Response from Airlines in case any Help is Required}

Figure 7 below represents the customers' satisfaction level on the service of Airlines in case any help is required. It is clear from the graph that one-third of the sample was neutral, while 56 participants were dissatisfied and one-third of the sample was satisfied. Thus, almost all responses were equal.

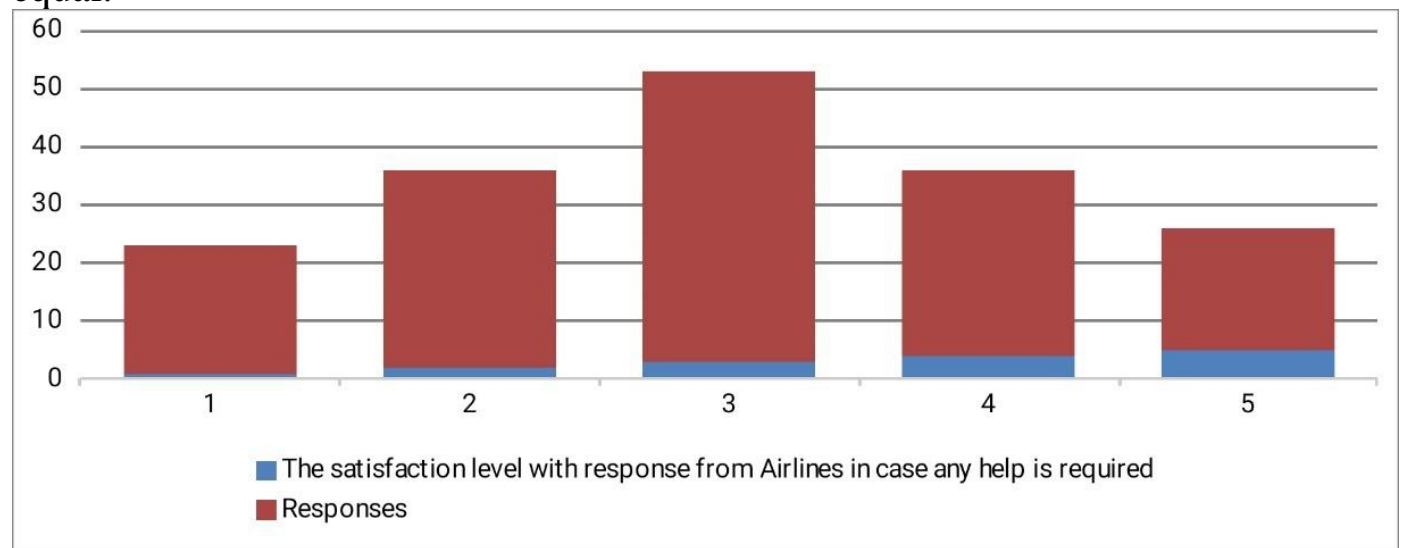

Figure 7. Satisfaction with response from Airlines in case any help is required

\section{The Satisfaction Level with Service Level of Employees during the Check in Process}

This chart demonstrates customer satisfaction of the service level of employees during the check in process. It is clear from the graph that all responses are close, satisfied response were 63 , dissatisfied were 55, and 41 were natural.

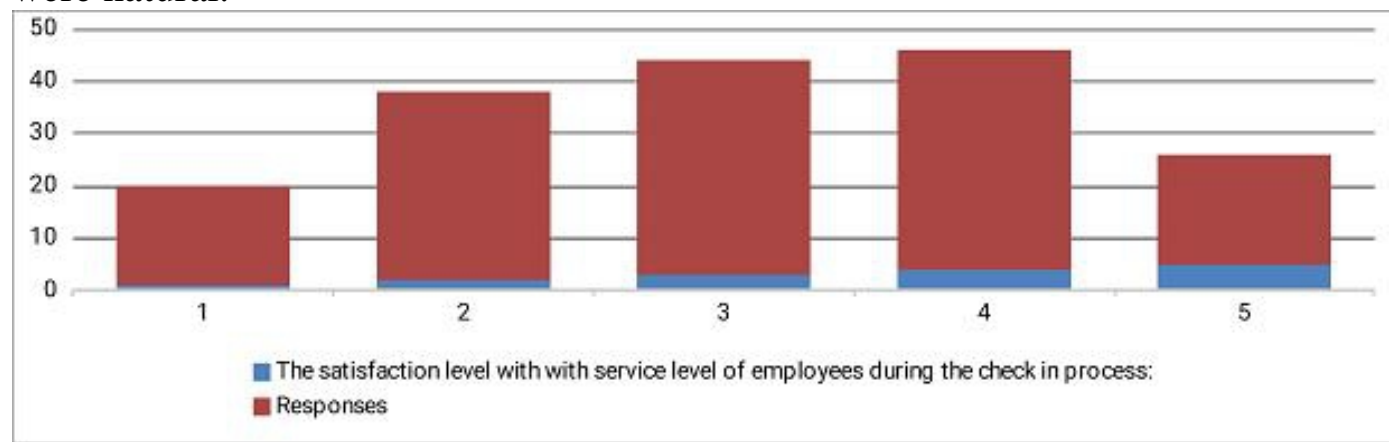

Figure 8. Satisfaction with response service level of employees during the check in process

\section{The Satisfaction Level with Tickets Prices}

The graph illustrates that $37 \%$ of the participants were satisfied with ticket prices, $29 \%$ of the sample was not satisfied with the ticket prices, and $28 \%$ were natural. 


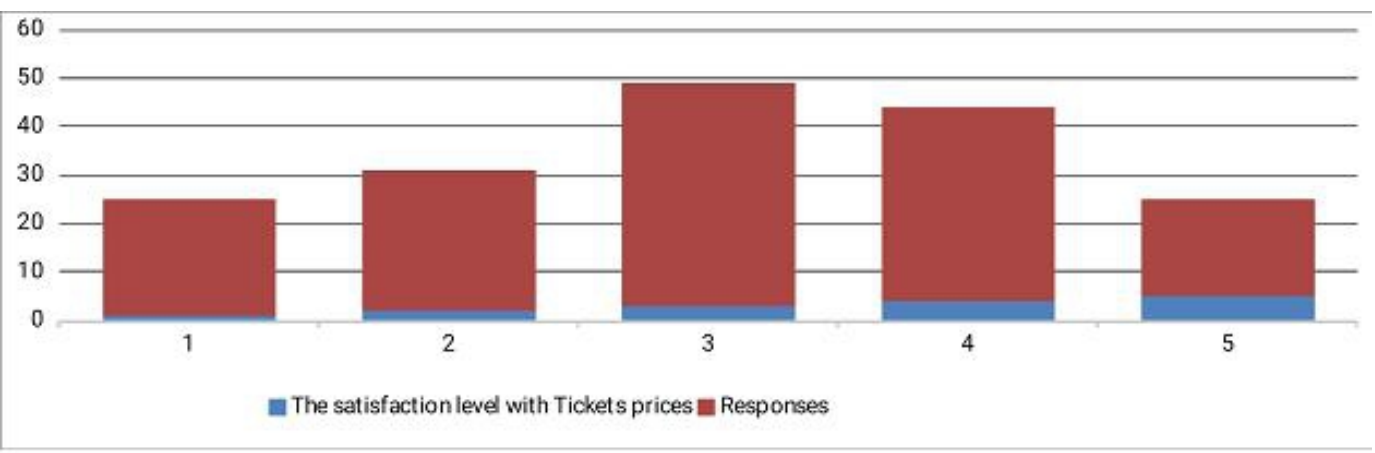

Figure 9. Satisfaction with Ticket Prices

\section{The Satisfaction Level with Food Quality Provided during Flight}

This figure represents the customers' satisfaction level on the service of food quality provided during flight. It is clear from the graph below that approximately one-third of the sample was neutral, 50 participants were dissatisfied, and more than one-third of the sample was satisfied.

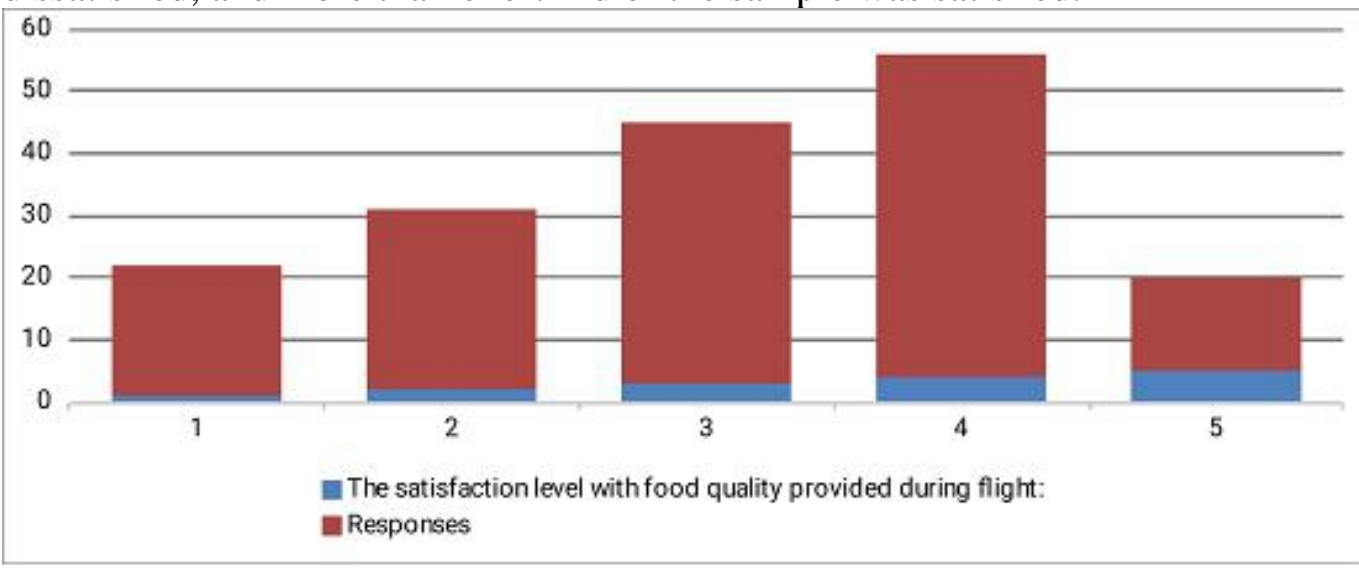

Figure 10. Satisfaction with food quality provided during flight

8. The Satisfaction Level with Rate of Experience while using the Online Services Provided by the Airlines; For Example, Online Booking of Tickets, Seats, etc.

As shown in the graph below, the majority of traveler's experience rate while using the online services provided by the airlines such as online booking of tickets, seats, etc. were satisfied with 66 passengers. However, the dissatisfaction level was lower with only 54 passengers while the remaining 39 passengers were neutral. 


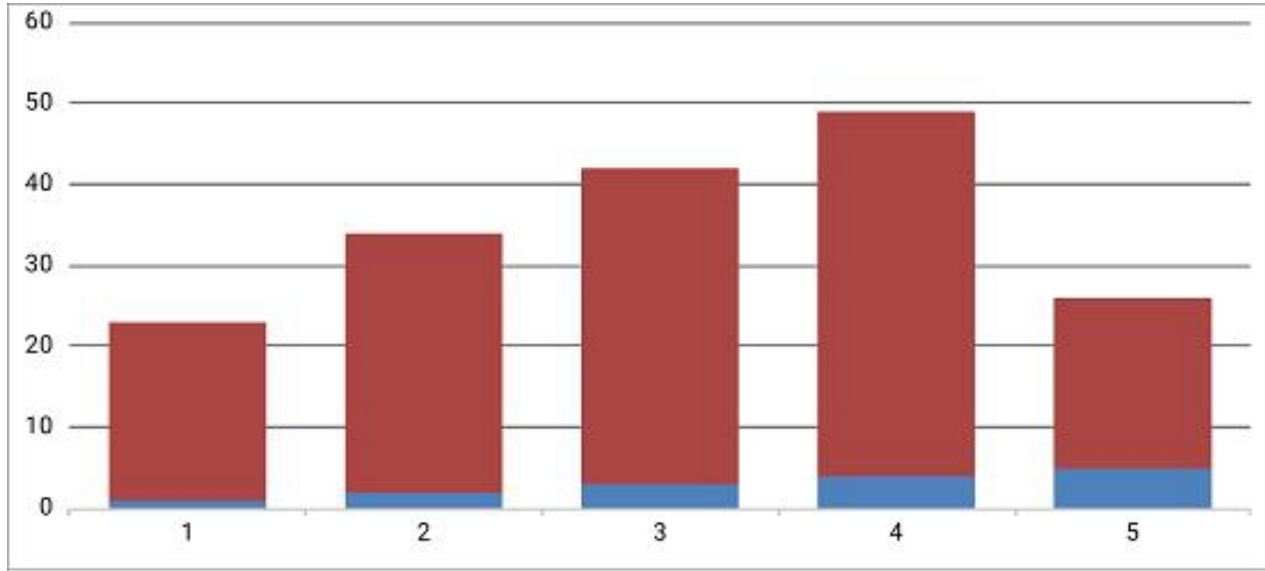

Figure 11. The satisfaction level with rate of experience while using the online services provided by the airlines; for example, online booking of tickets, seats, etc.

9. The Satisfaction Level with Entertainment Programs Provided by the Airlines are Satisfactory; For Example, the Type or Numbers of Movies, TV Shows, Documentaries, Games, and Others

In this graph below, all percentages were close to each other and the majority of passengers were satisfied with 65 responses regarding the entertainment programs provided by the airlines such as type or numbers of movies, TV shows, documentaries, and games. On the other hand, 60 responses of passengers were dissatisfied. Lastly, around 34 of the passengers were neutral.

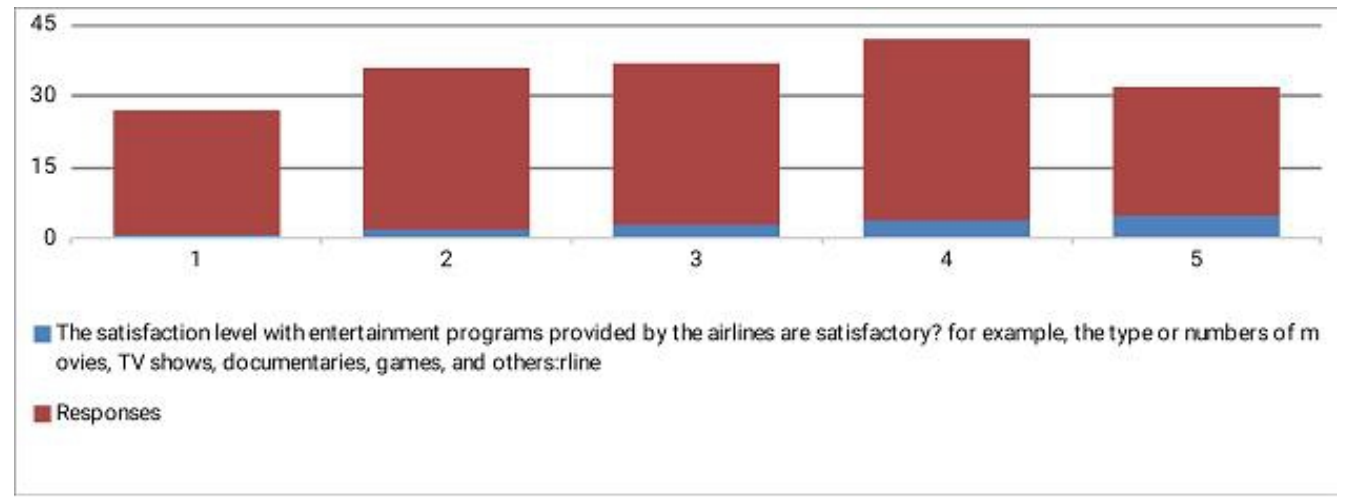

Figure 12. Satisfaction level with entertainment programs provided by the airlines

\section{- The Satisfaction Level Airline's Facility Design}

When the travelers were asked about their satisfaction level with airline's facility design, fortunately the majority of passengers were satisfied with 74 responses as shown in the graph below. However, the dissatisfaction level was 58 responses only and the response of neutral was accumulated for 27 responses. 


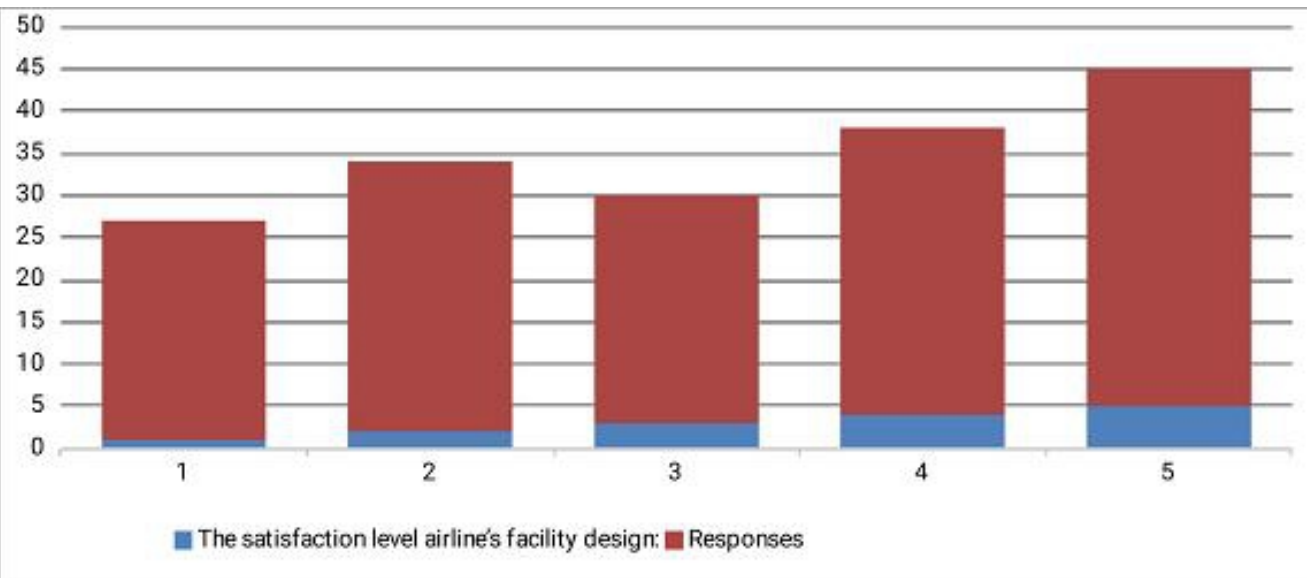

Figure 13. The satisfaction level airline's facility design

\section{Conclusion and Recommendations}

In conclusion, we dived deeply into the airlines industry in regards to customer's satisfaction with Saudi Arabia Airlines and found that the overall satisfactory level was below average. This means that we have a lot of problems to be tackled by the airlines industry stakeholders in Saudi Arabia to attain excellence in customer services. In general, Females \& Domestic travelers are more satisfied than Males \& International Travelers, which gives us an indication that Females are being served better in Saudi Airline industry than Males. In addition, Domestic travelers are more satisfied with the services, timing, and prices more than the international travelers. Therefore, this gives us an indication that this may be due to government subsidies on local flights tickets prices which have a significant effect on their satisfactory level. On the other hand, the local flights have a short time frame, and most of the travelers are not after quality food, baggage management or entertainment etc. As a result, the satisfaction level is high.

\section{Recommendations}

Baggage Management is recommended for all passengers. A better treatment of the baggage in terms of handling it, preventing it from getting dirty and damaged, are essential for all passengers. This is in addition to its arrival time after each flight which must be much faster than the current lead time. Flights Timing mostly for International passengers should be put into consideration. Flights delay is one of the most annoying things that can ever happen to a passenger. In domestic flight, this is rarely happening. However, in International flights, it happens very often. Thus, this affects the satisfactory level of the customers and leaves them with a bad feeling, bad impression, and a hurting word-of-mouth about the Airline's service level. A counter measure 
to be taken is a good option or compensations in case of any delay even if it was less than 15 minutes. Food Quality should be provided mostly for Female passengers. Additionally, a survey must be conducted only on food with the focus on females because females are most often dissatisfied with quality of food compared to males. Also, different varieties should be served with a higher quality for sure.

\section{References:}

1. Alotaibi, M. (2015). Evaluation of "AIRQUAL" scale for measuring airlines service quality and its effect on customer satisfaction and loyalty. [online] Dspace.lib.cranfield.ac.uk. Available at: https://dspace.lib.cranfield.ac.uk/handle/1826/9651

2. Climis, R. (2018). Factors Affecting Customer Retention in the Airline Industry. Journal of Management and Business Administration. Central Europe, Vol. 24, No.4. Available at: https://www.degruyter.com/view/j/jmbace.2016.24.issue4/jmba.ce.2450-814.182/jmba.ce.2450-7814.182.xml

3. Daft, J. \& Albers, S. (2013). A conceptual framework for measuring airline business model convergence. Journal of Air Transport Management, Volume 28, Pages 47-54.

4. Daft, J. \& Albers, S. (2015). An empirical analysis of airline business model convergence. Journal of Air Transport Management, Volume 46, Pages 3-11.

5. Edmund K. Burke, Patrick De Causmaecker, Jeroen Mulder Marc Paelinck \& Greet Vanden Berghe (2010). A multi-objective approach for robust airline scheduling. Computers \& Operations Research. Volume 37, Issue 5, May 2010, Pages 822-832

6. Elias, N., Mohamed, H., \& Arridha, R. (2015). A study on the factors affecting customer satisfaction in online airline services. International Journal of Business Information Systems, 20(3), pp.274-288.

7. Gambo, M. (2016). Service Quality and Customer satisfaction among domestic air passenger in Nigeria. International Journal of Business and Management Studies, Vol 8, No. 2, pp. 32-49.

8. Ganjihal, S. (2016). Customer Satisfaction in Airline Industry United Kingdom (British Airways) |Customer Satisfaction Airlines. [online] Scribd. Available at: https://www.scribd.com/doc/63966944/Customer-Satisfaction-inAirline-Industry-United-Kingdom-British-Airways

9. Jahmani, A. (2017). The Effect of Riyal Jordanian Airlines Services. International Journal of Business and Society, Vol 18(S3), pp.519-530.

10. Jens Clausen, Allan Larsen, Jesper Larsen, \& Natalia Rezanova (2010). Disruption management in the airline industry-Concepts, 
models and methods Computers \& Operations Research. Volume 37, Issue 5, May 2010, Pp. 809-821.

11. Khan, U. \& Khan, N. (2014). Customer Satisfaction in Airline Industry. Dept. of Business Administration, Main Campus, Iqra University, Karachi, [online] 76 . 12, pp.63-76. Available at: https://pdfs.semanticscholar.org

12. Kos Koklic, M., Kukar-Kinney, M., \& Vegelj, S. (2017). An investigation of customer satisfaction with low-cost and full-service airline companies. Journal of Business Research, 80, 188-196.

13. Laming, C. \& Mason, K. (2014). Customer experience - An analysis of the concept and its performance in airline brands. Research in Transportation Business and Management, 10, 15-25.

14. Oyewole, P. (2015). Consumer Purchase related factors and satisfaction. Journal of International Business Disciplines, Vol. 10 (2), pp.20-35.

15. Steven, A., Dong, Y., \& Dresner, M. (2012). Linkages between customer service, customer satisfaction and performance in the airline industry: Investigation of non-line arities and moderating effects. Transportation Research, part E(48), pp.743-754.

16. Wu, H.-C., \& Cheng, C.-C. (2013). A hierarchical model of service quality in the airline industry. Journal of Hospitality and Tourism Management, Volume 20, Pages 13-22. 